\title{
Susceptibility of whey protein isolate to oxidation and changes in physicochemical, structural, and digestibility characteristics
}

\author{
Xianchao Feng, ${ }^{*}$ Chenyi Li, ${ }^{*}$ Niamat Ullah, ${ }^{*}$ Jiqianrui Cao, ${ }^{*}$ Yongli Lan, ${ }^{*}$ Wupeng Ge, ${ }^{*}$ Robert M. Hackman, $\dagger$ \\ Zhixi Li, ${ }^{*}$ and Lin Chen*1 \\ ${ }^{*}$ College of Food Science and Engineering, Northwest A\&F University, Yangling, Shaanxi, China 712100 \\ †Department of Nutrition, University of California, Davis 95616
}

\begin{abstract}
Oxidation is an important factor for denaturing of whey protein isolate (WPI) during food processing. We studied the effects of chemical oxidation on physicochemical and structural changes along with in vitro digestibility of WPI in this work. Evaluation of physicochemical changes showed that carbonyl level and dityrosine content increased, whereas total and free thiol group levels decreased for oxidized WPI samples. For the structural changes, protein aggregation was measured by surface hydrophobicity, turbidity, and particle diameter, which was increased for oxidized WPI samples. The increase of the secondary structure $\beta$-sheets and antiparallel $\beta$-sheet also supported the aggregation of oxidized WPI. A direct quantitative relationship between physicochemical and structural changes and protein digestibility indicated that oxidation-related damage restricts the susceptibility of WPI to proteases. In conclusion, WPI had high susceptibility to oxidative stress, and both physicochemical and structural changes caused by severe oxidative stress could decrease the rate of in vitro digestibility of WPI.
\end{abstract}

Key words: aggregation, in vitro digestion, physicochemical changes, whey protein isolates, structural changes

\section{INTRODUCTION}

Whey protein is an important component of milk, as it represents $20 \%$ of total protein and is much higher in human milk than in bovine milk (Hoffman and Falvo, 2004). During cheese production, whey is the main protein left over after coagulation of milk. Because of its high amounts of EAA and branched-chain AA, whey protein is an important functional food additive (Kimball and Jefferson, 2006). Beneficial functions of branched-chain AA are well documented (e.g., it

Received May 13, 2015.

Accepted July 3, 2015.

${ }^{1}$ Corresponding author: melody-sara@hotmail.com helps in prevention of cardiovascular disease, cancer, diabetes, weight gain, and so on), and they can also help in decreasing plasma insulin and improving lipid profile (Krissansen, 2007). Whey protein is commonly marketed as a dietary supplement and used to improve nutritional value and functional properties of formulated foods (e.g., dairy foods, bakery products, sports drinks; de Wit, 1998; Rawdkuen and Benjakul, 2008).

Reactive oxygen species and reactive nitrogen species, which are produced during food treatment (i.e., cooking, drying, storing, and so on), attack food protein very easily. Oxidation and denaturation of protein not only alter physiochemical, but also alter structural properties of protein during food treatments. Carbonyls, disulfide, and dityrosine bridges generated by oxidation of AA residues cause the polymerization and aggregation of proteins and change its secondary and tertiary structure (Sun et al., 2011; Cui et al., 2012). Structure is the base characteristic of protein, and characteristics such as hydrophobicity will be changed following the changes in structure and numerous biological processes will be affected. The effect of protein oxidation on neurological disorders has been studied and a strong association with neurodegenerative disorders, prion diseases, and with many forms of cancer has been noted (Blennow et al., 2006). In the food industry, protein oxidation happens in almost every food process, which reduces the digestibility of the protein by digestive tract enzymes (Bax et al., 2013).

When whey protein isolate (WPI) is used as a functional additive, foods are exposed to radical-mediated oxidative stress during processing and protein oxidation occurs; however, the association between oxidized WPI and digestibility is poorly documented. The relationship between digestion and physicochemical and structural changes caused by chemical oxidation of WPI has not been fully elucidated yet; that is, whether chemical oxidation has negative or positive effects has yet to be determined. The current study was designed to evaluate the physicochemical and structural changes of oxidized WPI, along with its nutritional quality, with the hypothesis that certain processes (drying, cooking, 
and storing) could have a negative effect on the nutritional quality of WPI.

\section{MATERIALS AND METHODS}

\section{WPI Oxidation}

Whey protein isolate (Davisco Foods International Inc., Eden Prairie, MN), at $20 \mathrm{mg} / \mathrm{mL}$ (wt/vol) final concentration, was incubated for 3,6 , and $9 \mathrm{~h}$ at room temperature $\left(25^{\circ} \mathrm{C}\right)$ in a free radical-generating system (20 mM PBS at pH 6.0, $0.1 \mathrm{mM} \mathrm{FeCl} 3,5 \mathrm{~m} M \mathrm{H}_{2} \mathrm{O}_{2}$, and $0.1 \mathrm{~m} M$ ascorbic acid). The oxidized WPI samples were recorded as 3-h hydrogen peroxide (HP), 6-h HP, and 9-h HP samples, separately. At each time point, to prevent subsequent oxidation, Trolox (MP Biomedicals LLC, Solon, OH), butylated hydroxyanisole (BHA; Aladdin Industrial Corporation, Fengxian, Shanghai, China), and EDTA (1 $\mathrm{m} M$ final concentration of each) was added. Control samples were dissolved with the same PBS buffer without the oxidizing agents. All the samples were lyophilized before further analysis.

\section{Carbonyls Analysis}

Modified method of Oliver et al. (1987) was used for carbonyls analysis. 2,4-Dinitrophenylhydrazine (DNPH) was used to detect carbonyl groups of WPI in the form of protein hydrazones. Two aliquots of 150 $\mu \mathrm{L}$ of WPI solution $(20 \mathrm{mg} / \mathrm{mL})$ were centrifuged at $10,000 \times g$ at $4^{\circ} \mathrm{C}$ for $5 \mathrm{~min}$. One precipitation was treated with $1 \mathrm{~mL}$ of $0.2 \%$ (wt/vol) DNPH in $2 \mathrm{~N} \mathrm{HCl}$, whereas the other was treated with an equal volume of 2 $N \mathrm{HCl}$ without DNPH. All the samples were incubated at room temperature under agitation for $1 \mathrm{~h}$; then, the solutions were precipitated with TCA (20\% TCA, wt/ vol, final concentration). The precipitate was washed 3 times with ethyl acetate $(1: 1, \mathrm{vol} / \mathrm{vol})$ to eliminate free DNPH. The WPI was dissolved by $1 \mathrm{~mL}$ of $6 \mathrm{M}$ guanidine $\mathrm{HCl}$ at $\mathrm{pH}$ 6.5. The protein concentration of WPI was calculated in $2 \mathrm{~N} \mathrm{HCl}$ control. The carbonyl concentration was measured in the treated sample by measuring the absorption of protein hydrazones at $370 \mathrm{~nm}$ with the molar extinction coefficient of 21,000 $M^{-1} \mathrm{~cm}^{-1}$. The results were expressed as nanomoles of DNPH fixed per milligram of protein.

\section{Dityrosine}

The WPI samples were dissolved in $20 \mathrm{~m} M$ PBS ( $\mathrm{pH}$ 6.0) to get a final concentration of $1 \mathrm{mg} / \mathrm{mL}$. The contents of dityrosine in samples were measured using F-4600 FL spectrophotometer (Hitachi, Tokyo, Japan) with excitation at $325 \mathrm{~nm}$ and emission at $395 \mathrm{~nm}$ (ex- citation slit $=5 \mathrm{~nm}$; emission slit $=5 \mathrm{~nm}$; Davies et al., 1987; Cui et al., 2012). The dityrosine contents were expressed as absorbance units per milligram of protein.

\section{Total and Free Thiol Group Content}

Thiol oxidation was measured according to a modified method of Ellman (1959) using 5,5'-dithiobis (2-nitrobenzoic acid) (Martinaud et al., 1997). The WPI was dissolved with $20 \mathrm{mM}$ PBS buffer at $\mathrm{pH} 6.0$ to get 10 $\mathrm{mg} / \mathrm{mL}$ solution. One hundred microliters was diluted with $1 \mathrm{~mL}$ of $8 M$ urea in $100 \mathrm{~m} M$ PBS at $\mathrm{pH} 8.0$ for total thiol group (TT); the other $100 \mu \mathrm{L}$ was diluted with $1 \mathrm{~mL}$ of $100 \mathrm{mM}$ PBS at $\mathrm{pH} 6.0$ without urea for free thiol group (FT). Then, $0.5 \mathrm{~mL}$ of $4 \mathrm{mg} / \mathrm{mL}$ $5,5^{\prime}$-dithiobis (2-nitrobenzoic acid) was added and incubated in the dark at $25^{\circ} \mathrm{C}$ for $30 \mathrm{~min}$. The absorbance at $386 \mathrm{~nm}$ was measured against a blank of $100 \mu \mathrm{L}(20$ $\mathrm{m} M$ PBS) using an absorption coefficient of 13,600 $\mathrm{M}^{-1}$ $\mathrm{cm}^{-1}$. The results are expressed as nanomoles of thiol per milligram of protein. Thiol group level embedded inside the protein $(\mathbf{T E})$ was calculated as $\mathrm{TE}=\mathrm{TT}$ content - FT group content.

\section{WPI Surface Hydrophobicity}

Surface hydrophobicity of WPI was determined using hydrophobic chromophore bromophenol blue (BPB) by following Cui et al. (2012) with some modifications. This method is based on fixing BPB with insoluble myofibrillar proteins and quantifying the amount of bound $\mathrm{BPB}$. The BPB solution ( $50 \mu \mathrm{L}, 1 \mathrm{mg} / \mathrm{mL})$ was added to WPI solution $(2 \mathrm{mg} / \mathrm{mL})$ in $20 \mathrm{mM}$ PBS at $\mathrm{pH} 6$ and vortexed well. Then, the WPI solution was shaken at room temperature for $10 \mathrm{~min}$ in dark and centrifuged at $4,000 \times g$ for $15 \mathrm{~min}$ at $4^{\circ} \mathrm{C}$. The free $\mathrm{BPB}$ in the supernatant was measured at $595 \mathrm{~nm}$. Control was prepared without WPI. The percent of bound BPB $(\mu \mathrm{g})$ by WPI was calculated as an index of hydrophobicity; each determination was performed in duplicate:

$$
\begin{gathered}
\text { bound } \mathrm{BPB}(\mu \mathrm{g})=50 \mu \mathrm{g} \\
\times\left(\mathrm{OD}_{\text {control }}-\mathrm{OD}_{\text {sample }}\right) / \mathrm{OD}_{\text {control }},
\end{gathered}
$$

where OD = optical density.

\section{Turbidity}

The formazin suspension prepared by mixing $7.5 \mathrm{~mL}$ of the hydrazine sulfate solution $(10 \mathrm{mg} / \mathrm{mL})$ and 7.5 $\mathrm{mL}$ of hexamethylenetetramine solution $(100 \mathrm{mg} / \mathrm{mL})$ with final volume of $100 \mathrm{~mL}$, which was defined as a 600 formazin turbidity units (FTU) primary reference 
standard. The turbidity of WPI solutions $(10 \mathrm{mg} / \mathrm{mL})$ were measured at room temperature by determination of absorbance at $600 \mathrm{~nm}$ with standards from 0 to 600 FTU. The turbidity of protein solution was expressed as FTU per milligram of protein.

\section{Particle Diameter of WPI}

The average particle diameter of WPI aggregates was measured by dynamic light scattering using the Zetasizer Nano ZS (Malvern Instruments Ltd., Malvern, UK). Samples were diluted with $20 \mathrm{mM}$ PBS (pH 6.4) buffer to a final concentration of $1 \mathrm{mg} / \mathrm{mL}$ and measured. All measurements were performed in triplicate. The aggregates in the sample were expressed as the intensity measured by Nano ZS.

\section{Fourier Transform Infrared Spectroscopy}

The WPI samples were mixed well with potassium bromide powder before pressing into a tablet. Fourier transform infrared spectrum was investigated using a Bruker Vertex 70 (Bruker, Ettlingen, Germany) in the transmittance mode with a resolution of $4 \mathrm{~cm}^{-1}$ in the range of 400 to $4,000 \mathrm{~cm}^{-1}$ during 64 scans. Fourier self-deconvolution of the overlapping amide I band components $\left(1,585-1,710 \mathrm{~cm}^{-1}\right)$ was made possible by using OMNIC Peak Resolve software (Thermo Fisher Scientific, Waltham, MA). The curve-fitting procedure was performed by the Gauss formula (Sakudo et al., 2009). Protein secondary structures ( $\alpha$-helix, $\beta$-sheet, $\beta$-turn, and random coil) were diagnosed accordingly to the previous reported studies (Sakudo et al., 2009; Carbonaro and Nucara, 2010). The area corresponding to each secondary structure was calculated and expressed as a percentage of the sum of areas.

\section{In Vitro Digestibility}

In vitro pepsin digestion of WPI was analyzed using the method of Bax et al. (2012) with little modification. The WPI samples $(18.75 \mathrm{mg})$ were suspended in 25 $\mathrm{mL}$ of $33 \mathrm{~m} M$ glycine buffer (pH 1.82). Gastric pepsin was used to hydrolyze protein. The concentration of the gastric pepsin was made $40 \mathrm{U} / \mathrm{mg}$ and were applied at $37^{\circ} \mathrm{C}$ for $90 \mathrm{~min}$. Trichloroacetic acid $45 \%$ was used to terminate the digestion with different time intervals (i.e., 0, 5, 10, 15, 20, 25, 30, 40, 60, and $90 \mathrm{~min}$ ). After cessation of digestion, temperature of the samples was regulated by keep it on ice for $1 \mathrm{~h}$. Hydrolyzed peptides were collected in supernatant after centrifugation at $4,000 \times g$ for $15 \mathrm{~min}$ at $4^{\circ} \mathrm{C}$ and was measured at 280 nm with 96-well plates using Epoch (Biotek, Winooski, VT). Analyses were repeated twice for reproducibility.
The same procedure was used for in vitro digestibility of WPI by trypsin and $\alpha$-chymotrypsin after digested by pepsin for $1 \mathrm{~h}$ (Bax et al., 2012).

The digestion kinetics curves were described using the previous mathematical model (Gatellier and SantéLhoutellier, 2009). Primary parameters for the curve were estimated, such as initial optical density (initial OD), maximal digestion (ODmax), half-life time (is the time when the OD $=1 / 2$ ODmax), initial slope $(\Delta \mathrm{OD} / \mathrm{h})$, and maximal rate of digestion (Gatellier and Santé-Lhoutellier, 2009).

\section{Statistical Analysis}

We used SPSS (ver. 16.0, SPSS Inc., Chicago, IL) for all analyses. One-way ANOVA and the StudentNewman-Keuls (SNK) test were applied to determine the significance of the main effects $(P<0.05)$. All the data were expressed as mean \pm standard deviation of duplicate determinations.

\section{RESULTS AND DISCUSSION}

\section{Physicochemical Changes of Oxidized WPI}

During processing, AA residues are subjected to attack by oxygen radicals and transformed into carbonyls groups, particularly those with $\mathrm{NH}$ or $\mathrm{NH}_{2}$, such as Asn, Gln, Arg, Lys, His, and Trp (Sante-Lhoutellier et al., 2007). Results of the current study showed that the content of protein carbonyls of oxidized WPI were higher than nonoxidized WPI, and carbonyl content of oxidized WPI samples increased in a time-dependent manner $(P<0.05$; Table 1; Cui et al., 2012). These results were in agreement with previous observations on skeletal muscle proteins (Morzel et al., 2006; Bax et al., 2012). At each time point, carbonyl contents of oxidized WPI samples were significantly higher. The effect of oxidizing time on carbonyl content measured in the present study was fairly consistent with the effect of heating time (Santé-Lhoutellier et al., 2008). Actually, the formation of carbonyls can be caused by protein oxidation even without an oxidizing agent during storage (Bax et al., 2012). Thiol group level is another important parameter to estimate the denaturation of protein on the secondary structure, such as $\beta$-sheet structure and $\alpha$-helices. Consequently, the thiol group level was usually used to monitor the susceptibility of protein to oxidation (Wu et al., 2006). The oxidized WPI had lower FT, TT, and TE compared with nonoxidized WPI $(P<0.05$; Table 1$)$. The decrease of FT and TT indicated the accessible cysteine residues located at both the protein surface and embedded inside the protein were attacked by free radicals. 
Table 1. Effect of oxidation on the carbonyl content, dityrosine content, and thiol group levels of whey protein isolates (WPI) samples

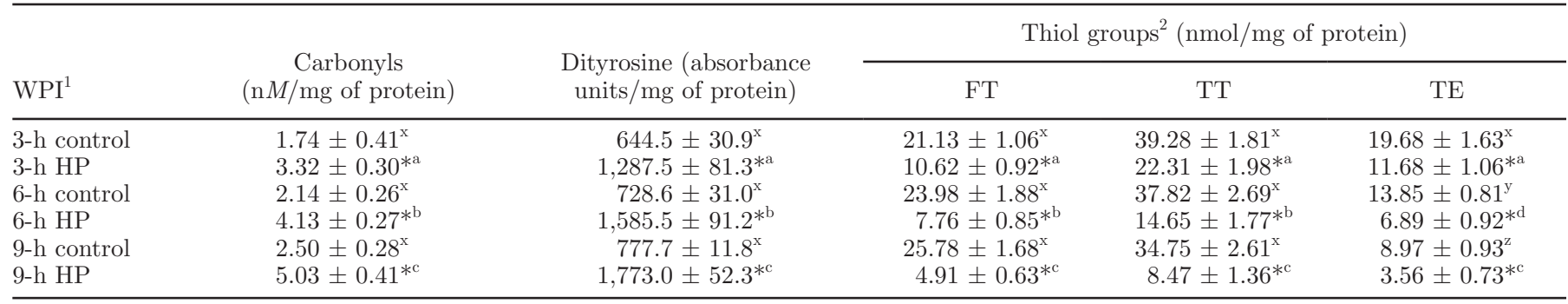

${ }^{\mathrm{a}-\mathrm{d}}$ Different superscripts for WPI samples means significant difference $(P<0.05)$.

${ }^{\mathrm{x}-\mathrm{z}}$ Different superscripts for nonoxidized WPI (control) means significant difference $(P<0.05)$.

${ }^{1} \mathrm{HP}=$ hydrogen peroxide.

${ }^{2} \mathrm{FT}=$ free thiol; $\mathrm{TT}=$ total thiol; $\mathrm{TE}=$ thiol embedded in protein.

*Significant $(P<0.05)$ compared with nonoxidized WPI.

The decrease of thiol group supported the formation of disulfide bonds, which is very important for protein structure (Cui et al., 2012). The dityrosine could also be formed during protein oxidation. The dityrosine formation in oxidized WPI significantly increased with time, which had the similar changes as the carbonyl for both oxidized and nonoxidized WPI samples (Table 1). Dityrosine was produced in all oxidized WPI samples (Cui et al., 2012). A previous study reported amounts of dityrosine detected when the protein samples were exposed to $\mathrm{H}_{2} \mathrm{O}_{2}$ to be sufficient (Morzel et al., 2006), which may be explained by the fact that the tyrosyl
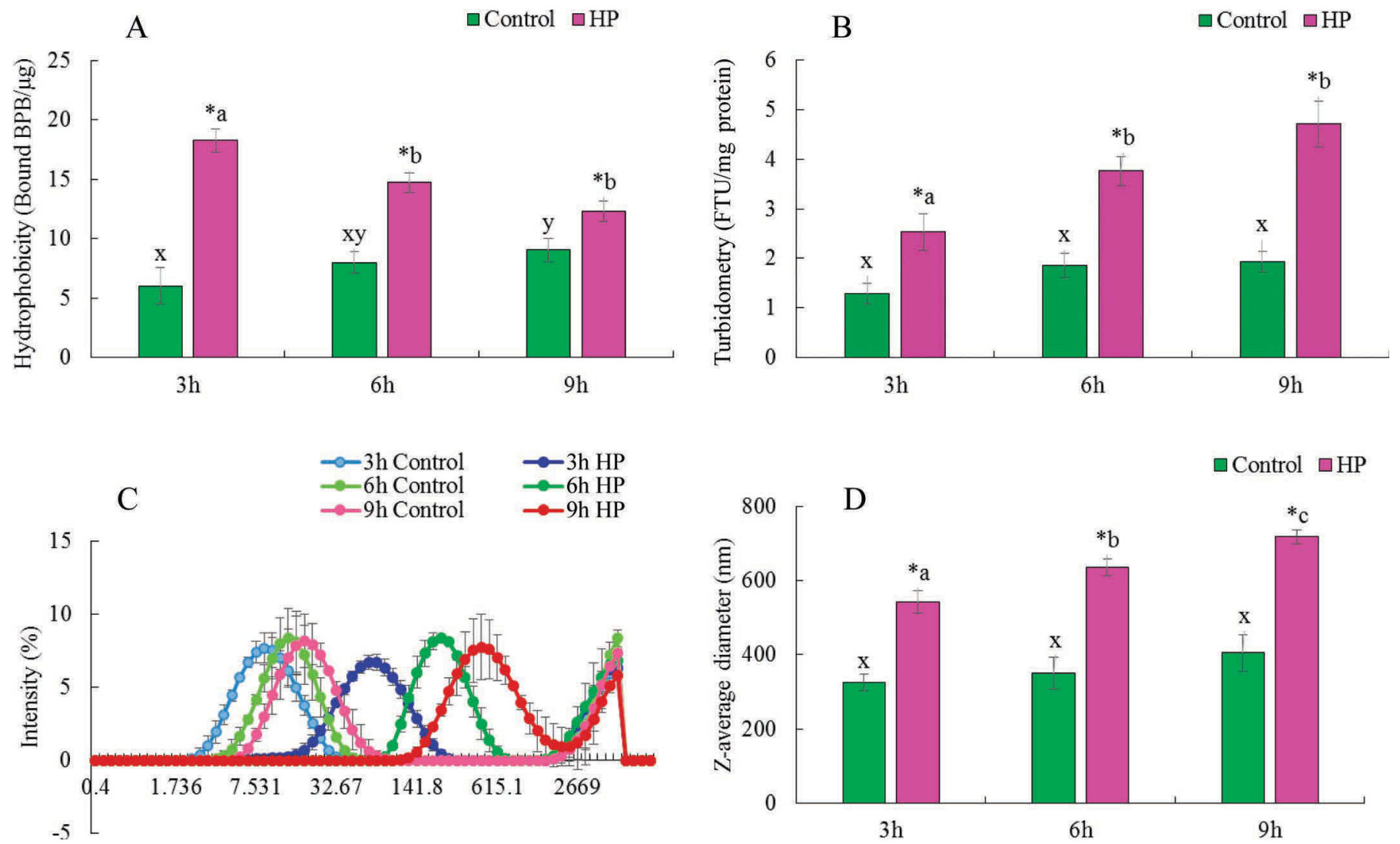

Figure 1. Effect of oxidation on hydrophobicity (bound bromophenol blue, BPB/ $\mu \mathrm{g} ; \mathrm{A}$ ), turbidity (Formazin turbidity units, FTU; B), particle size distributions (\%; C), and Z-average diameter (nm; D) of whey protein isolate (WPI) samples. An asterisk $(*)$ means significant $(P<$ $0.05)$ compared with nonoxidized WPI. Different lowercase letters $(\mathrm{x}, \mathrm{y})$ for nonoxidized WPI (control) means significant difference $(P<0.05)$ different lowercase letters $(\mathrm{a}-\mathrm{c})$ for oxidized WPI [hydrogen peroxide $(\mathrm{HP})$ ] means significant difference $(P<0.05)$. The analysis was repeated 3 times; errors bars indicate standard deviation. Color version available online. 
radical could be formed and enhance the formation of dityrosine under $\mathrm{H}_{2} \mathrm{O}_{2}$ activation (Østdal et al., 2000).

\section{Structural Changes of Oxidized WPI}

Aggregates of proteins may arise by a covalent or noncovalent manner. Covalent aggregates arise when chemical bond is formed between 2 or more monomers. Formation of disulfide bonds resulting from previously unpaired free thiols is a common mechanism for covalent aggregation (Andya et al., 2003). Oxidation of Tyr also results in covalent aggregation by the formation of dityrosine (Giulivi and Davies, 1994). Compared with covalent aggregates, noncovalent protein interaction also contributes to protein aggregation (Cromwell et al., 2006). Protein turbidity, unlike dityrosine and disulfide bonds, could indicate the noncovalent protein-protein associations (Cromwell et al., 2006). In current study, the turbidity of WPI solutions increased drastically by 2.25-, 2.51-, and 3.27-fold when oxidized for 3, 6, and $9 \mathrm{~h}$ compared with nonoxidized WPI (Figure 1B). This proved that noncovalent protein-protein associations were also enhanced by oxidation. Changes in surface hydrophobicity reflect changes in chemical and physical characteristics of the protein structure (Sun et al., 2011). Consequently, protein hydrophobicity has been widely applied to assess the protein oxidation and denaturation (Sante-Lhoutellier et al., 2007). In current study, oxidized WPI had higher hydrophobicity than nonoxidized WPI $(P<0.05$; Figure $1 \mathrm{~A})$. The mechanism of such changes could be explained by exposure of hydrophobic AA buried inside native protein during oxidation, which enhanced the surface hydrophobicity of protein (Grune et al., 2004). However, the surface hydrophobicity of oxidized WPI decreased with oxidizing time $(P<0.05$; Figure $1 \mathrm{~A})$, whereas it increased for nonoxidized WPI (Figure 1A). This may have been caused by protein aggregation partially shielding the effect of unfolding in strongly oxidized WPI ( $\mathrm{Li}$ et al., 2012). Protein oxidation under heating conditions breaks the hydrogen bonds and van der Waals forces and exposes the interior hydrophobic AA (Chelh et al., 2006). Likewise, smaller molecules from WPI hydrolysis caused by incubation at $25^{\circ} \mathrm{C}(3,6$, or $9 \mathrm{~h})$ maybe the reason for the increased surface hydrophobicity of nonoxidized WPI (Yongsawatdigul and Park, 1999).

Dynamic light scattering has been reported as a parameter for complementary information of protein aggregates, which could detect even small aggregates of protein that cannot be detected by electrophoresis (Zhang and Vardhanabhuti, 2014). The particle size and Z-average diameter of oxidized WPI samples were higher and increased with oxidizing time $(P<0.05$; Figure $1 \mathrm{C}$ and $\mathrm{D}$ ), which proved that the aggregates
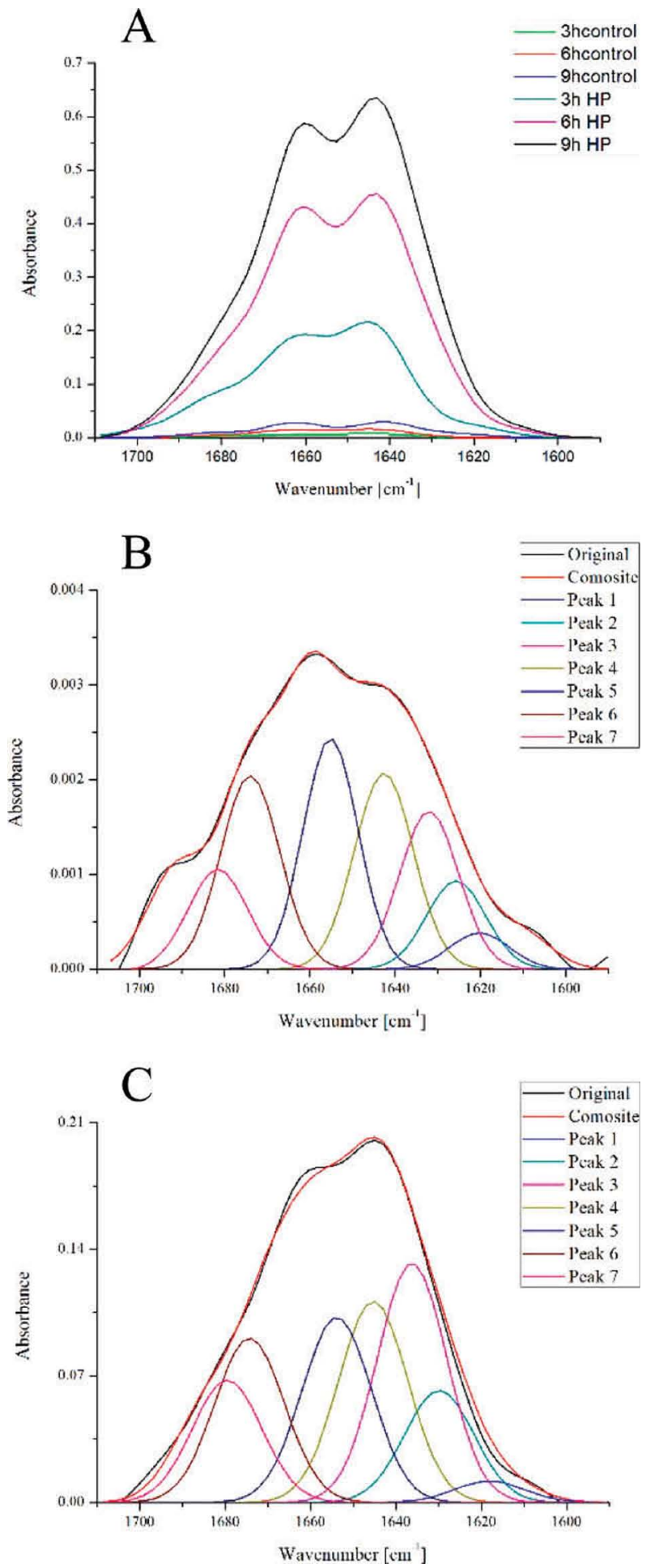

Figure 2. Deconvolution and curve-fitted amide I region $[\mathrm{A}=\mathrm{com}-$ posite of whey protein isolate; $\mathrm{B}=3$-h control; $\mathrm{C}=3$-h hydrogen peroxide (HP)]. The amide I region of Fourier transform infrared spectra (composite) was separated into 7 peaks (B and C; the sequence starting with 7 , then $6,5,4,3,2,1$ in turn from 1,700 to $1,600 \mathrm{~cm}^{-1}$ ). The ratio of area to composite represents the corresponding percentage of each structure; peaks 1 (aromatic ring vibration of tyrosine residues), 2 to 3 and 7 ( $\beta$-sheet), 4 (random coil), 5 ( $\alpha$-helix), and 6 ( $\beta$-turn) are indicated accordingly. Color version available online. 
of oxidized WPI were enhanced. However, WPI aggregation of nonoxidized WPI samples increased slightly with time. This indicated that thermal denaturation at low temperature $\left(25^{\circ} \mathrm{C}\right)$ mainly caused the increase of surface hydrophobicity of protein more than protein aggregates (Bax et al., 2012). The changes of particle size and Z-average diameter also supported the loss of thiol groups, the formation of disulfide bonds, dityrosine, and improvement of surface hydrophobicity protein, whereas all these changes can promote aggregation of WPI in radical-mediated oxidation. The aggregation measured by particle size and Z-average diameter also supported the increase of turbidity in oxidized WPI samples (Sun et al., 2011; Cui et al., 2012).

The amide I region is mainly associated with the $\mathrm{C}$ $=\mathrm{O}$ stretching vibration (70-85\%) and $\mathrm{C}-\mathrm{N}$ groups (10-20\%; Carbonaro and Nucara, 2010). The range in area between 1,600 and $1,700 \mathrm{~cm}^{-1}$ could reflect the degree of oxidation. The larger area of the amide I region in oxidized WPI samples supported its higher carbonyl content compared with the nonoxidized samples (Figure $2 \mathrm{~A}$ ). The peaks 2,3 , and 7 are caused by the intermolecular $\beta$-sheets, which increased with time and was higher in oxidized WPI samples compared with that of nonoxidized WPI $(P<0.05$; Table 2$)$. The $\beta$-sheets are the indicator of protein aggregation (Sun et al., 2011); these results also supported the changes of particles size from dynamic light scattering. Moreover, peak 3 was caused by parallel $\beta$-sheets, whereas peaks 2 and 7 were generally considered antiparallel $\beta$-sheets (Pelton and McLean, 2000). The increased ratio of antiparallel $\beta$-sheets (peaks 2 and 7) and decrease of $\alpha$-helix (peak 5 ) in oxidized WPI samples indicated that the protein rearranged the second structure during oxidation $(P<$ 0.05; Table 2; Sakudo et al., 2009). Studies had reported the association of peak 1 with aromatic ring vibration of tyrosine residues. As a result, the decrease of ratio of peak 1 in oxidized WPI may be caused by formation of dityrosine during oxidation process $(P<0.05$; Table $2)$. The increased ratio of random coil and decreased $\alpha$-helix may have occurred because of unfolded proteins (random coil) folded into $\beta$-sheet during rebuilding of secondary structure (Sun et al., 2011).

A correlation study was conducted to establish links between all parameters (Table 3). Results show that FT and TT embedded inside the protein were negatively correlated with carbonyl levels $(P<0.05)$, whereas dityrosine were positively correlated with carbonyl levels $(P<0.05)$. Carbonyls content is considered as an important indicator for the degree of oxidation. The decrease of thiol group was caused by disulfide bonds formation in oxidized WPI samples (Sun et al., 2011). Dityrosine formed from Tyr residues cross-linking had a similar tendency with disulfide bonds (Cui et al., 2012). Turbidity and particle diameter of WPI aggregation were positively correlated with carbonyls. However, no significantly positive correlations between turbidity and particle diameter with the surface hydrophobicity were observed. This could be explained by the fact that carbonyl groups generated by the formation of amide bonds with residual amino groups improved WPI polymerization, but protein aggregation partially shielded the effect of unfolding in strongly oxidized WPI (Sante-Lhoutellier et al., 2007). The significant correlations between carbonyls, TT, dityrosine, turbidity, and particle diameter with the second structure of WPI (aromatic ring vibration of tyrosine residues, $\beta$-sheets, and $\alpha$-helix) indicated that rearrangement of second structure caused by oxidation could explain the physiochemical and structural changes of oxidized WPI samples (Sun et al., 2011; Cui et al., 2012).

\section{In Vitro Digestibility of Oxidized WPI}

Protein nutritional quality was assessed by the in vitro digestibility method. Gastric pepsin was used, which

Table 2. Secondary structural ratio of proteins (\%) in different whey protein isolates (WPI) samples

\begin{tabular}{|c|c|c|c|c|c|c|}
\hline & $\begin{array}{l}\text { Aromatic ring } \\
\text { vibration }\end{array}$ & $\beta$-Sheet & Random coil & $\alpha$-Helix & $\beta$-Turn & $\beta$-Antiparallel \\
\hline $\mathrm{WPI}^{1}$ & Peak 1 & Peak 2,3 , and 7 & Peak 4 & Peak 5 & Peak 6 & Peak 2 and 7 \\
\hline 3-h control & $2.82 \pm 0.12^{\mathrm{x}}$ & $33.99 \pm 0.49^{\mathrm{x}}$ & $18.62 \pm 0.28^{\mathrm{x}}$ & $28.17 \pm 0.42^{\mathrm{x}}$ & $16.39 \pm 0.23^{\mathrm{x}}$ & $19.24 \pm 0.57^{\mathrm{x}}$ \\
\hline $3-\mathrm{h}$ HP & $2.12 \pm 0.13^{* \mathrm{a}}$ & $36.16 \pm 0.49^{* a}$ & $18.59 \pm 0.37^{\mathrm{a}}$ & $26.52 \pm 0.34^{* \mathrm{a}}$ & $16.61 \pm 0.40^{\mathrm{a}}$ & $20.92 \pm 0.28^{* a}$ \\
\hline 6-h control & $2.53 \pm 0.13^{\mathrm{xz}}$ & $34.77 \pm 0.41^{\mathrm{x}}$ & $18.44 \pm 0.26^{\mathrm{x}}$ & $27.65 \pm 0.35^{\mathrm{x}}$ & $16.60 \pm 0.34^{\mathrm{x}}$ & $19.56 \pm 0.48^{\mathrm{x}}$ \\
\hline 6-h HP & $1.83 \pm 0.16^{* a b}$ & $37.44 \pm 0.35^{* \mathrm{~b}}$ & $18.43 \pm 0.81^{\mathrm{a}}$ & $25.82 \pm 0.23^{* a}$ & $16.47 \pm 0.06^{\mathrm{a}}$ & $22.08 \pm 0.29^{* b}$ \\
\hline 9-h control & $2.48 \pm 0.14^{\mathrm{yz}}$ & $34.76 \pm 0.25^{\mathrm{x}}$ & $18.90 \pm 0.28^{\mathrm{x}}$ & $27.44 \pm 0.24^{\mathrm{x}}$ & $16.42 \pm 0.14^{\mathrm{x}}$ & $19.83 \pm 0.35^{\mathrm{x}}$ \\
\hline 9-h HP & $1.52 \pm 0.15^{* \mathrm{~b}}$ & $38.53 \pm 0.48^{* c}$ & $18.67 \pm 0.76^{\mathrm{a}}$ & $24.94 \pm 0.49^{* \mathrm{~b}}$ & $16.34 \pm 0.37^{\mathrm{a}}$ & $22.56 \pm 0.35^{* b}$ \\
\hline
\end{tabular}

${ }^{\mathrm{a}-\mathrm{c}}$ Different superscripts for WPI samples means significant difference $(P<0.05)$.

${ }^{\mathrm{x}-\mathrm{z}}$ Different superscripts for nonoxidized WPI (control) means significant difference $(P<0.05)$.

${ }^{1} \mathrm{HP}=$ hydrogen peroxide.

*Significant $(P<0.05)$ compared with nonoxidized WPI. 
Table 3. Correlation matrix between parameters of oxidative modification and protease activities ${ }^{1}$

\begin{tabular}{|c|c|c|c|c|c|c|c|c|c|c|c|c|c|c|c|c|c|c|}
\hline Item & CAR & $\mathrm{FT}$ & $\mathrm{TT}$ & $\mathrm{TE}$ & $\mathrm{SH}$ & TUR & DIT & $\mathrm{PD}$ & ARV & Sheet & Helix & ODP & ISP & MRP & HLTP & ODT $\alpha$ & IST $\alpha$ & $\operatorname{MRT} \alpha \quad H L T T \alpha$ \\
\hline CAR & 1 & & & & & & & & & & & & & & & & & \\
\hline FT & $-0.794^{*}$ & 1 & & & & & & & & & & & & & & & & \\
\hline TT & $-0.892^{* *}$ & $0.876^{* *}$ & 1 & & & & & & & & & & & & & & & \\
\hline $\mathrm{TE}$ & $-0.840^{*}$ & 0.577 & $0.767^{*}$ & 1 & & & & & & & & & & & & & & \\
\hline $\mathrm{SH}$ & 0.516 & -0.674 & -0.650 & -0.477 & 1 & & & & & & & & & & & & & \\
\hline TUR & $0.914^{* *}$ & $-0.811^{*}$ & $-0.893^{* *}$ & $-0.813^{*}$ & 0.503 & 1 & & & & & & & & & & & & \\
\hline DIT & $0.885^{* *}$ & $-0.883^{* *}$ & $-0.919^{* *}$ & $-0.753^{*}$ & 0.661 & $0.890^{* *}$ & 1 & & & & & & & & & & & \\
\hline PD & $0.898^{* *}$ & $-0.862^{* *}$ & $-0.919 * *$ & $-0.789^{*}$ & 0.648 & $0.895^{* *}$ & $0.916^{* *}$ & 1 & & & & & & & & & & \\
\hline ARV & $-0.908^{* *}$ & 0.726 & $0.906^{* *}$ & 0.725 & -0.617 & $-0.806^{*}$ & $-0.904^{* *}$ & $-0.909 * *$ & 1 & & & & & & & & & \\
\hline Sheet & $0.907^{* *}$ & $-0.847^{* *}$ & $-0.874^{* *}$ & $-0.796^{*}$ & 0.589 & $0.813^{*}$ & $0.812^{*}$ & $0.910^{* *}$ & $-0.916^{* *}$ & 1 & & & & & & & & \\
\hline Helix & $-0.911^{* *}$ & $0.838^{*}$ & $0.868^{* *}$ & 0.713 & -0.605 & $-0.869^{* *}$ & $-0.908^{* *}$ & $-0.814^{*}$ & $0.818^{*}$ & $-0.917^{* *}$ & 1 & & & & & & & \\
\hline ODP & $0.903^{* *}$ & $-0.812^{*}$ & $-0.903^{* *}$ & $-0.841^{*}$ & 0.638 & $0.888^{* *}$ & $0.896^{* *}$ & $0.911^{* *}$ & $-0.907^{*}$ & $0.898^{* *}$ & $-0.909^{* *}$ & 1 & & & & & & \\
\hline ISP & $-0.773^{*}$ & $0.912^{* *}$ & $0.856^{* *}$ & 0.545 & -0.665 & $-0.796^{*}$ & $-0.867 * *$ & $-0.839^{*}$ & $0.815^{*}$ & $-0.837^{*}$ & $0.823^{*}$ & $-0.783^{*}$ & 1 & & & & & \\
\hline MRP & $-0.773^{*}$ & $0.910^{* *}$ & $0.853^{* *}$ & 0.539 & -0.644 & $-0.798^{*}$ & $-0.864^{* *}$ & $-0.835^{*}$ & $0.812^{*}$ & $-0.836^{*}$ & $0.822^{*}$ & $-0.777^{*}$ & $0.919^{* *}$ & 1 & & & & \\
\hline HLTP & $0.796^{*}$ & -0.441 & -0.615 & -0.542 & 0.109 & $0.811^{*}$ & 0.606 & 0.713 & -0.735 & 0.565 & $-0.751^{*}$ & 0.496 & -0.338 & -0.653 & 1 & & & \\
\hline ODT $\alpha$ & $0.889^{* *}$ & $-0.858^{* *}$ & $-0.915^{* *}$ & $-0.790^{*}$ & 0.683 & $0.881^{* *}$ & $0.912^{* *}$ & $0.918^{* *}$ & $-0.905^{* *}$ & $0.902^{* *}$ & $-0.909^{* *}$ & $0.913^{* *}$ & $-0.834^{*}$ & $-0.829^{*}$ & 0.578 & 1 & & \\
\hline IST $\alpha$ & $-0.822^{*}$ & $0.902^{* *}$ & $0.873^{* *}$ & 0.600 & -0.568 & $-0.847^{* *}$ & $-0.880^{* *}$ & $-0.858^{* *}$ & $0.843^{*}$ & $-0.869^{* *}$ & $0.853^{* *}$ & $-0.807^{*}$ & $0.905^{* *}$ & $0.909^{* *}$ & -0.742 & $-0.845^{* *}$ & 1 & \\
\hline MRT $\alpha$ & $-0.785^{*}$ & $0.906^{* *}$ & $0.854^{* *}$ & 0.546 & -0.596 & $-0.813^{*}$ & $-0.865^{* *}$ & $-0.836^{*}$ & $0.815^{*}$ & $-0.844^{* *}$ & $0.825^{*}$ & $-0.776^{*}$ & $0.914^{* *}$ & $0.916^{* *}$ & -0.493 & $-0.824^{*}$ & $0.915^{* *}$ & 1 \\
\hline HLTT $\alpha$ & $0.879^{* *}$ & $-0.843^{*}$ & $-0.872^{* *}$ & -0.694 & 0.342 & $0.890^{* *}$ & $0.869^{* *}$ & $0.867^{* *}$ & $-0.863^{* *}$ & $0.885^{* *}$ & $-0.877^{* *}$ & $0.838^{* *}$ & $-0.835^{*}$ & $-0.842^{*}$ & $0.847^{* *}$ & $0.848^{* *}$ & $-0.886^{* *}$ & $-0.858^{* *}$ \\
\hline
\end{tabular}

${ }^{1} \mathrm{CAR}=$ carbonyl; FT $=$ free thiol group; TT $=$ total thiol group; TE $=$ thiol group level embedded inside the protein; SH $=$ surface hydrophobicity; TUR $=$ turbidity; DIT $=$ dityrosine; $\mathrm{PD}=$ particle diameter; $\mathrm{ARV}=$ aromatic ring vibration of tyrosine residues; Sheet $=\beta$-sheets; Helix $=\alpha$-helix; ODP $=$ ODmax-Pepsin; ISP $=$ initial slope-pepsin; $\mathrm{MRP}=$ maximal rate of digestion-pepsin; HLTP $=$ half-life time-pepsin; ODT $\alpha=$ ODmax-trypsin and $\alpha$-chymotrypsin; IST $\alpha=$ initial slope-trypsin and $\alpha$-chymotrypsin; MRT $\alpha$ $=$ maximal rate of digestion-trypsin and $\alpha$-chymotrypsin; HLTT $\alpha=$ half-life time-trypsin and $\alpha$-chymotrypsin.

$* P<0.05, * * P<0.01$ 
is most efficient in cleaving peptide bonds between hydrophobic and aromatic AA such as Phe, Trp, and Tyr (Sun et al., 2011). Proteolysis measured in oxidized WPI with gastric pepsin showed a biphasic response. That is why proteolysis rate of nonoxidized protein by gastric pepsin increased slightly with time, along with the related changes in initial slope and maximal rate of digestion (Figure 3). Conversely, the proteolysis rate of oxidized WPI by gastric pepsin decreased significantly with time (Figure 3). Proteolysis rates were highly and negatively correlated with carbonyl group level because carbonyl groups were formed by amide bonds with residual of amino groups. In current study, the maximal digestion and half-life time were positively correlated with carbonyl contents, turbidity, and dityrosine (Table 3 ). These results proved that the degradation potential of WPI had been improved by oxidation but needed a longer digestion time (Figure 3; Bax et al., 2012). The proteolysis rate was also negatively correlated with turbidity and particle diameter (Table 3 ). This could be explained by the fact protein aggregation has a negative effect on proteolysis susceptibility (Sante-Lhoutellier et
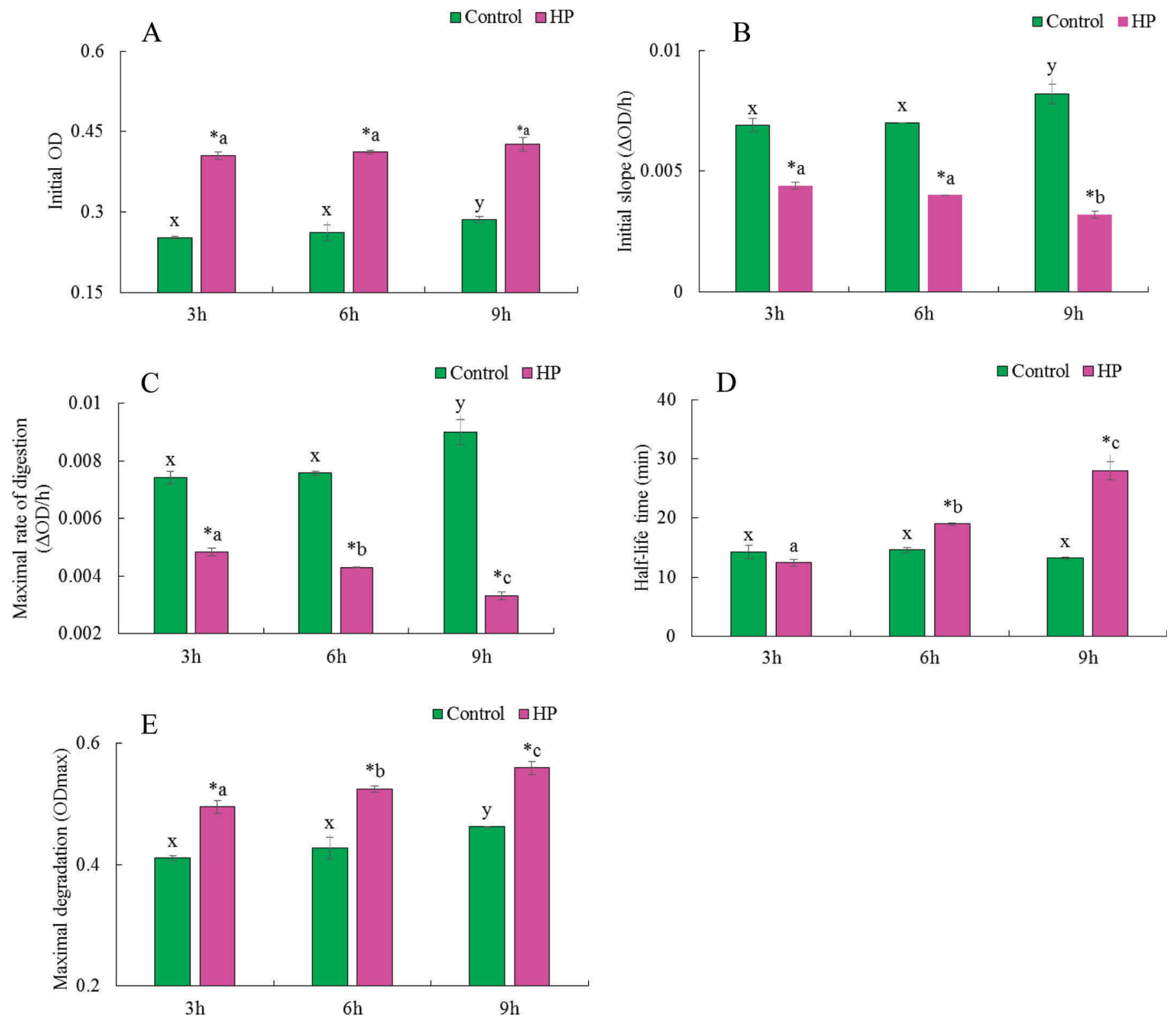

Figure 3. Effect of oxidation on in vitro pepsin digestion parameters $[\mathrm{A}=$ initial optical density $(\mathrm{OD})$; $\mathrm{B}=$ initial slope; $\mathrm{C}=$ maximal rate of digestion; $\mathrm{D}=$ half-life time; $\mathrm{E}=$ maximal degradation]. An asterisk $\left(^{*}\right)$ means significant $(P<0.05)$ comparing with nonoxidized whey protein isolate (WPI). Different lowercase letters (x,y) for nonoxidized WPI (control) means significant difference $(P<0.05)$; different lowercase letters $(\mathrm{a}-\mathrm{c})$ for oxidized WPI [hydrogen peroxide $(\mathrm{HP})]$ means significant difference $(P<0.05)$. Color version available online. 


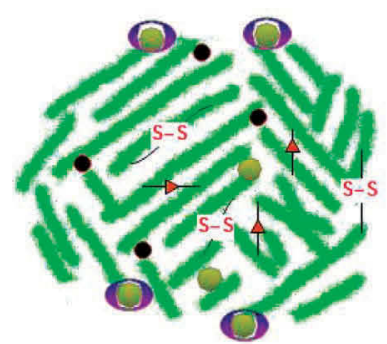

A

- Carbonyl

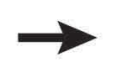

B

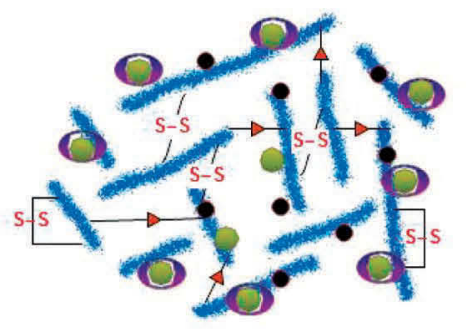

$\rightarrow$ Dityrosine
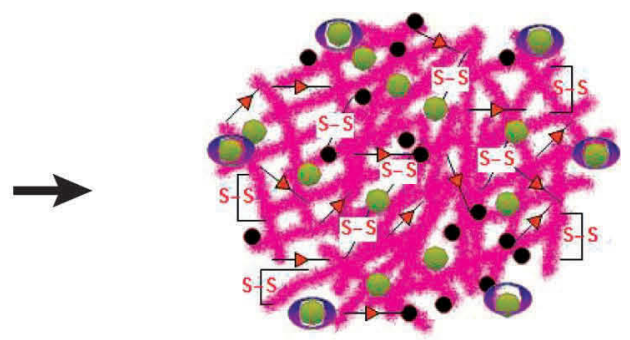

C S-S Disulfide bond

Figure 4. Proposed mechanism of pepsin action on whey protein isolate (WPI) samples (A = nonoxidized WPI; B = denaturated WPI; C = aggregated WPI). Color version available online.

al., 2007; Bax et al., 2012; Cui et al., 2012). Polymerization and aggregation have important effect on protein digestibility. Studies reported that heating at $90^{\circ} \mathrm{C}$ significantly increased the digestibility of $\beta-L G$, which is an important composition of whey protein (Peram et al., 2013). However, if heated at $90^{\circ} \mathrm{C}$ up to $24 \mathrm{~h}$, the aggregates of $\beta$-LG become more resistant to enzymatic digestion (Pinto et al., 2014). Myofibrillar proteins had a similar response to pepsin as well (Sante-Lhoutellier et al., 2007; Sun et al., 2011); however, properly modified myofibrillar proteins by oxidation were susceptible to proteolysis (Kamin-Belsky et al., 1996). In the case of myosin from myofibrillar proteins, oxidation decreased its susceptibility to gastric pepsin, pancreatic trypsin, and chymotrypsin under nonreducing conditions (Liu and Xiong, 2000). In the current work, protein denaturation occurred in nonoxidized WPI at $25(3,6$, or $9 \mathrm{~h})$ and $37^{\circ} \mathrm{C}(120 \mathrm{~min})$ in a water bath, characterized by visible but not significant protein conformation changes that maximized protein surface exposure to hydrophobic zones and, thus, promoted the bioaccessibility of pepsin to cleavage sites to a certain limit. Under free radical-generating systems, the aggregation process appears to outpace the thermal denaturation process; hence, the proteolysis rate of oxidized WPI decreased with oxidizing time (Bax et al., 2012).

Figure 4 proposes a mechanism of pepsin action based on the results of present study. Heating at $25^{\circ} \mathrm{C}$ in water bath $(3,6$, and $9 \mathrm{~h})$ produced subtle protein oxidation and proper conformational changes, enhancing the hydrolyzability by pepsin. Protein oxidized by free radical-generating systems led to protein aggregation and a decrease of protein hydrolyzability by pepsin. These results are in agreement with previous studies (Bax et al. 2012).

Both trypsin and $\alpha$-chymotrypsin are serine endopeptidases (Asante et al., 2014). Trypsin exclusively cleaves Arg or Lys residues on the $\mathrm{C}$ terminal, and $\alpha$-chymotrypsin preferentially cleaves peptide amide bonds and prefers hydrophobic residues, such as Tyr, Trp, or Phe (Kim et al., 2013; Asante et al., 2014). These AA are sensitive to free radicals and transformed into carbonyl groups (Kim et al., 2013). The digestion profile with trypsin and $\alpha$-chymotrypsin was similar with pepsin (Figure 5). For the nonoxidized protein, the initial slope, maximal rate of digestion, and maximal degradation increased (Figure 5). However, under free radical-generating systems, this initial slope and maximal rate of digestion of oxidized WPI decreased, whereas the half-time and maximal degradation increased (Figure 5). The mechanism of this phenomenon might be the same as that of pepsin digestion. Studies also reported the same results of the in vitro digestion of myofibrils protein (SanteLhoutellier et al., 2007; Sun et al., 2011; Bax et al., 2012). The initial slope, maximal rate of digestion, and maximal degradation with trypsin or $\alpha$-chymotrypsin were higher compared with pepsin. This could be explained by the sensitivity of hydrophobic residues to dual-enzyme system containing $\alpha$-chymotrypsin (Kim et al., 2013).

Pooling a full set of physicochemical, structural, and digestion results revealed that this data can be distinguished into 6 separate groups (Figure 6). On the first axis, nonoxidized WPI was opposed to the oxidized WPI. Carbonyl, turbidity, dityrosine, particle diameter, maximal rate of digestion, and half-life time were positively associated with the first axis (Bax et al., 2012). On the second axis, water bath time had a great effect on separation of WPI samples in both oxidization and non-oxidization conditions. Initial slope and degradation potential of both digestive proteases were associated positively to the second axis (Bax et al., 2012). This result indicated that both oxidizing agents and 
oxidizing time had influence on the physicochemical, structural, and nutritional quality of WPI.

\section{CONCLUSIONS}

The results of the current work demonstrate the remarkable susceptibility of WPI to hydroxyl radical oxidation at room temperature, which caused physicochemical and structural changes, such as the loss of thiol groups, formation of dityrosine and carbonyls, and increases in surface hydrophobicity, turbidity, and particle diameter. Oxidizing time had a great influence on oxidative changes; the aggregation and secondary structure changes had a negative effect on the nutri-
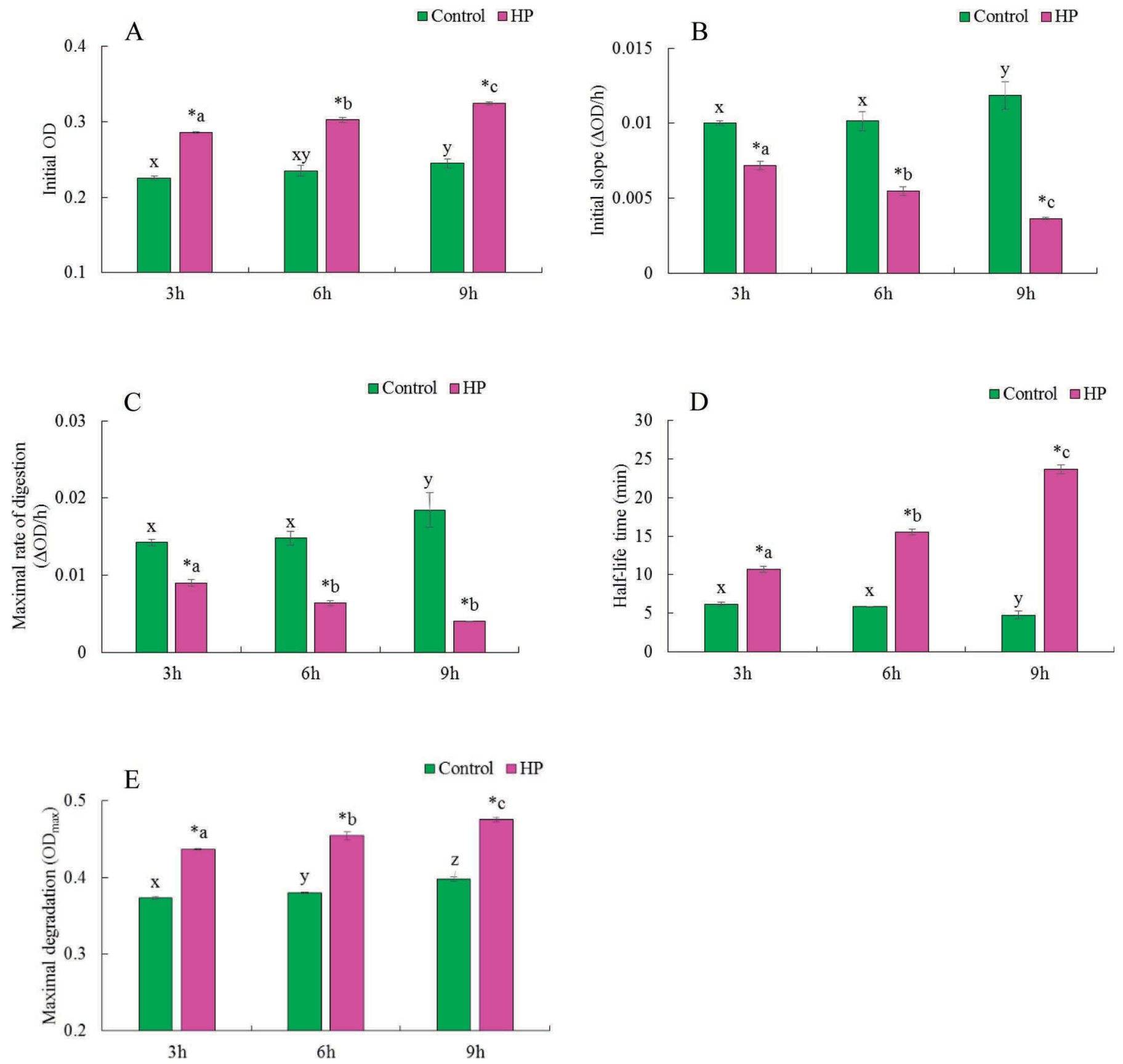

Figure 5. Effect of oxidation on in vitro trypsin and $\alpha$-chymotrypsin digestion parameters $[\mathrm{A}=$ initial optical density $(\mathrm{OD})$; $\mathrm{B}=$ initial slope; $\mathrm{C}=$ maximal rate of digestion; $\mathrm{D}=$ half-life time; $\mathrm{E}=$ maximal degradation]. An asterisk $(*)$ means significant $(P<0.05)$ compared with nonoxidized whey protein isolate (WPI). Different lowercase letters $(\mathrm{x}-\mathrm{z})$ for nonoxidized WPI (control) means significant difference $(P<0.05)$; different lowercase letters $(\mathrm{a}-\mathrm{c})$ for oxidized WPI [hydrogen peroxide $(\mathrm{HP})]$ means significant difference $(P<0.05)$. Color version available online. 


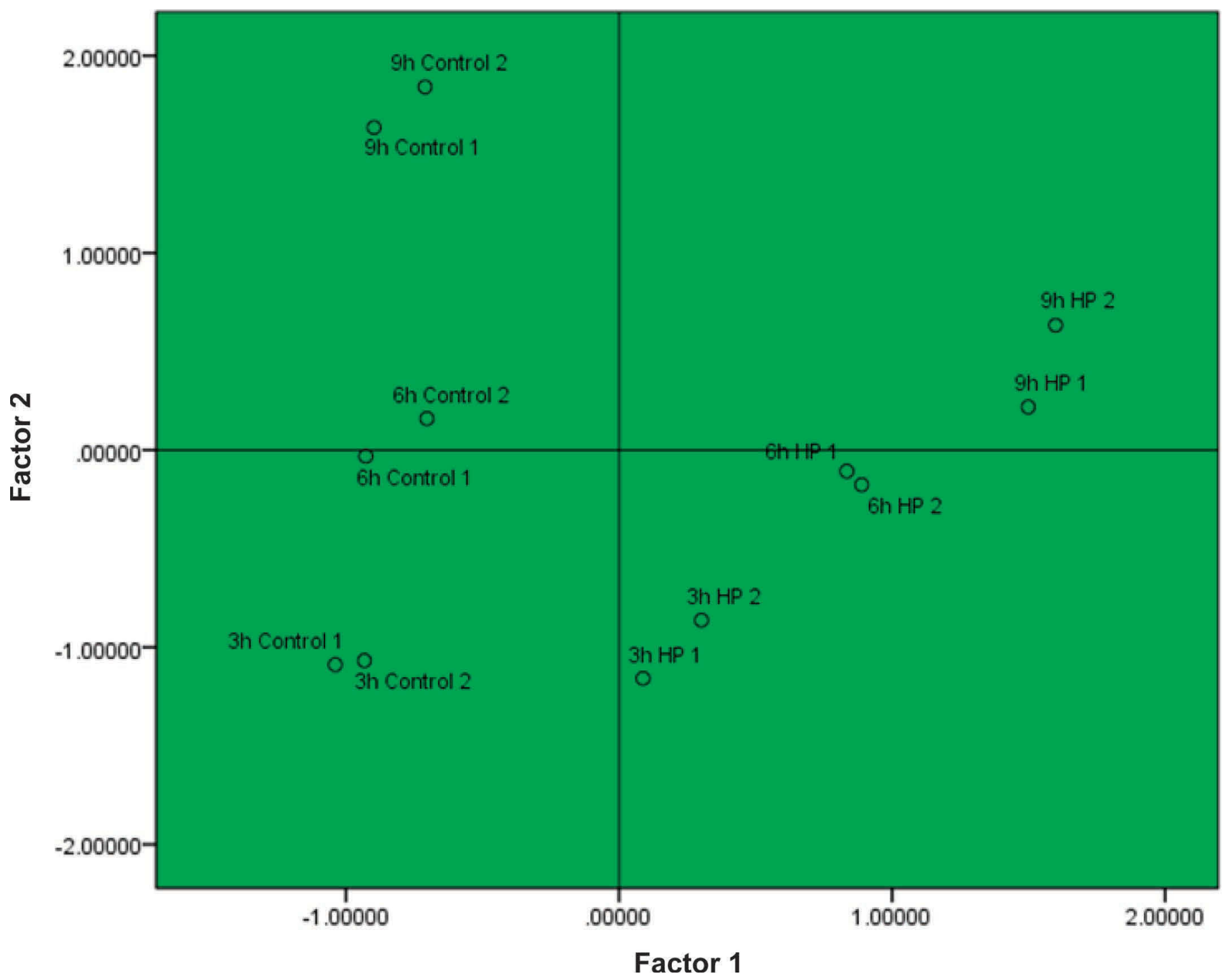

Figure 6. Principal component analysis plot: factor 1 versus factor 2 of all treatments. WPI $=$ whey protein isolate; HP $=$ hydrogen peroxide oxidized WPI. Color version available online.

tional quality of WPI. This statement is supported by decrease of initial slope, maximal rate of digestion in both digestive proteases, and increase of half-life time. Although in vitro digestion model approaches have limitations, especially in terms of intestinal absorption factors, it is possible to grasp a dynamic dimension of the in vitro digestion model and to compare a broad series of processing conditions. Hence, this study elucidated the hypothesis that free radicals from technological processes could decrease the nutritional quality of WPI. As proteins are important and widely used food additives, processing technologies need to reduce levels of protein oxidation to preserve the nutritional quality of food products.

\section{ACKNOWLEDGMENTS}

The authors thank Wu Ding, Yayun Hu, Li Jiang and Xiaoli Liu from College of Food Science and Engineering, Northwest A\&F University, for their technical support. This work was supported by National Natural Science Fund (Beijing, China) for Young Scholar (Grant No: 31401515).

\section{REFERENCES}

Andya, J. D., C. C. Hsu, and S. J. Shire. 2003. Mechanisms of aggregate formation and carbohydrate excipient stabilization of lyophilized humanized monoclonal antibody formulations. AAPS PharmSci 5:E10. 
Asante, V., J. Mortier, G. Wolber, and B. Koksch. 2014. Impact of fluorination on proteolytic stability of peptides: A case study with Q-chymotrypsin and pepsin. Amino Acids 46:2733-2744.

Bax, M. L., T. Sayd, L. Aubry, C. Ferreira, D. Viala, C. Chambon, D. Rémond, and V. Santé-Lhoutellier. 2013. Muscle composition slightly affects in vitro digestion of aged and cooked meat: Identification of associated proteomic markers. Food Chem. 136:12491262.

Bax, M.-L., L. Aubry, C. Ferreira, J.-D. Daudin, P. Gatellier, D. Rémond, and V. r. Santé-Lhoutellier. 2012. Cooking temperature is a key determinant of in vitro meat protein digestion rate: Investigation of underlying mechanisms. J. Agric. Food Chem. 60:25692576.

Blennow, K., M. J. de Leon, and H. Zetterberg. 2006. Alzheimer's disease. Lancet 368:387-403.

Carbonaro, M., and A. Nucara. 2010. Secondary structure of food proteins by Fourier transform spectroscopy in the mid-infrared region. Amino Acids 38:679-690.

Chelh, I., P. Gatellier, and V. Santé-Lhoutellier. 2006. Technical note: A simplified procedure for myofibril hydrophobicity determination. Meat Sci. 74:681-683.

Cromwell, M. E., E. Hilario, and F. Jacobson. 2006. Protein aggregation and bioprocessing. AAPS J. 8:E572-E579.

Cui, X., Y. L. Xiong, B. Kong, X. Zhao, and N. Liu. 2012. Hydroxyl radical-stressed whey protein isolate: Chemical and structural properties. Food Bioprocess Technol. 5:2454-2461.

Davies, K. J., M. Delsignore, and S. Lin. 1987. Protein damage and degradation by oxygen radicals. II. Modification of amino acids. J. Biol. Chem. 262:9902-9907.

de Wit, J. 1998. Nutritional and functional characteristics of whey proteins in food products. J. Dairy Sci. 81:597-608.

Ellman, G. L. 1959. Tissue sulfhydryl groups. Arch. Biochem. Biophys. $82: 70-77$.

Gatellier, P., and V. Santé-Lhoutellier. 2009. Digestion study of proteins from cooked meat using an enzymatic microreactor. Meat Sci. 81:405-409.

Giulivi, C., and K. J. Davies. 1994. Dityrosine: A marker for oxidatively modified proteins and selective proteolysis. Methods Enzymol. 233:363-371.

Grune, T., T. Jung, K. Merker, and K. J. Davies. 2004. Decreased proteolysis caused by protein aggregates, inclusion bodies, plaques, lipofuscin, ceroid, and 'aggresomes' during oxidative stress, aging, and disease. Int. J. Biochem. Cell Biol. 36:2519-2530.

Hoffman, J. R., and M. J. Falvo. 2004. Protein-Which is best? J. Sports Sci. Med. 3:118-130.

Kamin-Belsky, N., A. A. Brillon, R. Arav, and N. Shaklai. 1996. Degradation of myosin by enzymes of the digestive system: Comparison between native and oxidatively cross-linked protein. J. Agric. Food Chem. 44:1641-1646.

Kim, E.-K., J.-W. Hwang, Y.-S. Kim, C.-B. Ahn, Y.-J. Jeon, H. J. Kweon, Y. Y. Bahk, S.-H. Moon, B.-T. Jeon, and P.-J. Park. 2013. A novel bioactive peptide derived from enzymatic hydrolysis of Ruditapes philippinarum: Purification and investigation of its freeradical quenching potential. Process Biochem. 48:325-330.

Kimball, S. R., and L. S. Jefferson. 2006. Signaling pathways and molecular mechanisms through which branched-chain amino acids mediate translational control of protein synthesis. J. Nutr. $136: 227 \mathrm{~S}-231 \mathrm{~S}$.
Krissansen, G. W. 2007. Emerging health properties of whey proteins and their clinical implications. J. Am. Coll. Nutr. 26:713S-723S.

Li, C., Y. L. Xiong, and J. Chen. 2012. Oxidation-induced unfolding facilitates myosin cross-linking in myofibrillar protein by microbial transglutaminase. J. Agric. Food Chem. 60:8020-8027.

Liu, G., and Y. L. Xiong. 2000. Electrophoretic pattern, thermal denaturation, and in vitro digestibility of oxidized myosin. J. Agric. Food Chem. 48:624-630.

Martinaud, A., Y. Mercier, P. Marinova, C. Tassy, P. Gatellier, and M. Renerre. 1997. Comparison of oxidative processes on myofibrillar proteins from beef during maturation and by different model oxidation systems. J. Agric. Food Chem. 45:2481-2487.

Morzel, M., P. Gatellier, T. Sayd, M. Renerre, and E. Laville. 2006. Chemical oxidation decreases proteolytic susceptibility of skeletal muscle myofibrillar proteins. Meat Sci. 73:536-543.

Oliver, C. N., B.-W. Ahn, E. J. Moerman, S. Goldstein, and E. R. Stadtman. 1987. Age-related changes in oxidized proteins. J. Biol. Chem. 262:5488-5491.

Østdal, H., M. Bjerrum, J. Pedersen, and H. J. Andersen. 2000. Lactoperoxidase-induced protein oxidation in milk. J. Agric. Food Chem. 48:3939-3944

Pelton, J. T., and L. R. McLean. 2000. Spectroscopic methods for analysis of protein secondary structure. Anal. Biochem. 277:167176.

Peram, M. R., S. M. Loveday, A. Ye, and H. Singh. 2013. In vitro gastric digestion of heat-induced aggregates of $\beta$-lactoglobulin. J. Dairy Sci. 96:63-74.

Pinto, M. S., J. Léonil, G. Henry, C. Cauty, A. F. Carvalho, and S. Bouhallab. 2014. Heating and glycation of $\beta$-lactoglobulin and $\beta$-casein: Aggregation and in vitro digestion. Food Res. Int. 55:7076.

Rawdkuen, S., and S. Benjakul. 2008. Whey protein concentrate: Autolysis inhibition and effects on the gel properties of surimi prepared from tropical fish. Food Chem. 106:1077-1084.

Sakudo, A., H. Kuratsune, Y. H. Kato, and K. Ikuta. 2009. Secondary structural changes of proteins in fingernails of chronic fatigue syndrome patients from Fourier-transform infrared spectra. Clin. Chim. Acta 402:75-78.

Sante-Lhoutellier, V., L. Aubry, and P. Gatellier. 2007. Effect of oxidation on in vitro digestibility of skeletal muscle myofibrillar proteins. J. Agric. Food Chem. 55:5343-5348.

Sun, W., F. Zhou, M. Zhao, B. Yang, and C. Cui. 2011. Physicochemical changes of myofibrillar proteins during processing of Cantonese sausage in relation to their aggregation behaviour and in vitro digestibility. Food Chem. 129:472-478.

Wu, Z., H. C. Bertram, A. Kohler, U. Böcker, R. Ofstad, and H. J. Andersen. 2006. Influence of aging and salting on protein secondary structures and water distribution in uncooked and cooked pork. A combined FT-IR microspectroscopy and 1H NMR relaxometry study. J. Agric. Food Chem. 54:8589-8597.

Yongsawatdigul, J., and J. Park. 1999. Thermal aggregation and dynamic rheological properties of Pacific whiting and cod myosins as affected by heating rate. J. Food Sci. 64:679-683.

Zhang, S., and B. Vardhanabhuti. 2014. Effect of initial protein concentration and $\mathrm{pH}$ on in vitro gastric digestion of heated whey proteins. Food Chem. 145:473-480. 